\title{
Word and nonword superiority effects in a letter detection task
}

\author{
JOSHUA D. STALLER and JOSEPH S. LAPPIN \\ Vanderbilt University, Nashville, Tennessee 37240
}

\begin{abstract}
Subjects searched for predesignated consonant- letters embedded in strings of consonants, consonants and vowels, or consonants and numbers. In Experiments 1-3, detection was quicker in the consonant-vowel and consonant-number strings than in the consonant strings. Apparently, vowels and numbers were less confusable distractors than are nontarget consonants. Experiment 4 tested whether psychophysical or categorical information about letters and numbers enabled subjects to process consonant-vowel and consonant-number strings more quickly. Results indicated that psychophysical characteristics of target and distractor letters mediated both word and nonword superiority effects.
\end{abstract}

Can prior knowledge about a stimulus facilitate perception of that stimulus? Several sources suggest an affirmative answer (Julesz, 1971, p. 201; Lindsay \& Norman, 1972, p. 8; Sekuler \& Ball, 1977; Posner, Snyder, \& Davidson, Note 1), but there are few unequivocal experiments on this phenomenon (for relevant reviews see Egeth, 1967; Haber, 1966; Krueger, 1975). Many apparent examples of the phenomenon can be attributed more parsimoniously to the statistics of the stimulus without invoking specialized perceptual mechanisms or the direct influence of knowledge on perception (Green \& Birdsall, 1978; Lappin, 1978). Recent research, however, suggests a possible exception to this rulethe word superiority effect. Under conditions of tachistoscopic exposure, a letter is easier to identify when embedded in a word context than in a nonword context. Given the proper controls, this result seems to indicate that letter perception is directly enhanced by linguistic knowledge. Since Reicher's provocative demonstration of this effect in 1969, however, there has been considerable controversy about its interpretation, as well as the conditions under which it can be obtained.

For instance, Massaro and his co-workers (1973; Thompson \& Massaro, 1973) argued that redundancy was not properly controlled in the Reicher study. When Massaro told subjects in advance what target letters to search for, as well as the display position in which the targets would appear, no word superiority was found. Massaro concluded that when word

This research was supported by NIMH Fellowship MH-05499 to the first author and NSF Grant BMS-75-19103 to the second author. We thank Marty Singer and Brian Kottas for helpful advice throughout the project and Charles Eriksen and Dominic Massaro for insightful comments on an earlier version of this manuscript. Portions of this research were presented at the 1977 meeting of the Psychonomic Society. superiority is obtained, subjects have used their knowledge of orthographic redundancy to restrict the set of possible letter alternatives in words.

However, a follow-up study by Carr, Lehmkuhle, Kottas, Astor-Stetson, and Arnold (1976; see also Purcell, Stanovich, \& Spector, 1978) casts doubt on the generality of Massaro's conclusion. As in Massaro's work, Carr et al. gave subjects advance knowledge of target letters, but, in contrast with Massaro, Carr et al. introduced uncertainty about the display position in which the targets would appear. Under these conditions, word superiority was obtained. Carr et al. argued that their procedure equalized the use of orthographic redundancy in the word and nonword conditions. Thus, they conclude that linguistic knowledge directly enhances perception of target letters embedded in words.

The Carr et al. study has important theoretical implications since it suggests that knowledge can directly enhance perception. In the present study, we replicate the Carr et al. result and provide evidence for an alternative explanation of their finding. Our demonstration of both word and nonword superiority effects, using the Carr et al. letter detection procedure, indicates that linguistic knowledge per se need not mediate these effects. Instead, these results are determined by psychophysical and/or conceptual differences between target and distractor letters, as outlined below.

With regard to conceptual differences between letters, consider examples of the Carr et al. wordsPOT, APE, TAP-and nonwords-PKS, SPL, FQP. The word stimuli contain consonants and vowels, while the nonwords contain only consonants. Furthermore, subjects searched for target letters which were all consonants-P, R, C, G. Since all the targets were consonants, it seems possible that subjects used this knowledge to their advantage when processing word stimuli. The vowels in words might 
have been ruled out relatively quickly as nontargets on the basis of a categorical distinction between vowels and consonants. Indeed, experimental evidence indicates that such categorical information may facilitate the detection of targets in visual search tasks (Brand, 1971; Egeth, Jonides, \& Wall, 1972; Gleitman \& Jonides, 1976; Ingling, 1972; Jonides \& Gleitman, 1972, 1976; Schneider \& Shiffrin, 1977; Shiffrin \& Schneider, 1977).

A second (though not mutually exclusive) alternative to Carr et al. is based on the psychophysics of the letters. The letter distractors in words (A, E, O, T) were symmetrical, while those in nonwords were asymmetrical (K, S, L, F, Q). A variety of studies have shown that symmetrical patterns are often easier to process than asymmetrical ones (Julesz, 1971; Staller \& Sekuler, 1977; Pomerantz, 1977). In addition to symmetry, left-right pattern directionality may have also influenced detection; the targets $(\mathrm{P}, \mathrm{R}, \mathrm{C}, \mathrm{G})$ and nonword distractors $(\mathrm{K}, \mathrm{S}, \mathrm{L}, \mathrm{F}, \mathrm{Q})$ are all right-facing. Several studies have shown that subjects are sensitive to the left-right directionality of letters (Reinvang, 1972; Staller, 1974). Thus, letter symmetry as well as directionality may have mediated the word superiority effect obtained by Carr et al.'

In the following experiments, the role of conceptual categories in letter detection is evaluated in Experiments 1-3. The role of letter psychophysics is examined in Experiment 4. Taken together, the most parsimonious explanation of our results is that target/ distractor psychophysics mediated the word as well as nonword superiority effects obtained herein.

\section{EXPERIMENT 1}

In this experiment, we sought to replicate the Carr et al. finding that letters can be identified more readily in words than in nonwords. As in Carr et al., our subjects searched for predesignated consonant targets $(P, R, C, G)$ which appeared with equal probability at all display positions. In addition to the words and all-consonant nonwords illustrated above, we added a third condition-nonwords that contained both consonants and vowels. This new condition offers a preliminary test of the conceptual category hypothesis outlined above. If subjects use consonantvowel categories to expedite processing, then words and consonant-vowel nonwords should be processed with equal facility.

Several procedural differences between the present study and previous work are worth noting. The stimuli in the present study were clearly visible-there was no mask. Instead of producing errors by degrading the stimuli, we had subjects respond under speed stress. This was operationalized by giving analog feedback about response time to the subjects as they responded. Both the speed and accuracy of letter detection were measured. ${ }^{2}$

\section{Method}

Subjects. Five Vanderbilt University students ( 2 male, 3 female) were tested individually in five consecutive daily sessions. Each was paid $\$ 3$ per session.

Stimuli and Apparatus. There were three stimulus typeswords, consonant nonwords, and consonant-vowel nonwords. The words and consonant nonwords were those used by Carr et al: POT, ROT, COT, GOT, APE, ARE, ACE, AGE, TAP, TAR, TAC, TAG; and PKS, RKS, CKS, GKS, SPL, SRL, SCL, SGL, FQP, FQR, FQC, and FQG. The consonant-vowel nonwords (newly designed for this study) were POS, COS, GOS, ROS, UPE, URE, UCE, UGE, TEP, TER, TEC, and TEG. The stimuli were generated by a computer algorithm and presented on a cathode ray display (Tektronix Model $604, \mathrm{P}-15$ phosphor). The stimulus letters were composed by illuminating the appropriate dots in a 10 by 12 matrix. Individual letters subtended $25^{\prime} \times 30^{\prime}$ of visual angle, and neighboring letters were separated by $12.5^{\prime}$ of arc. The middle letter of the stimulus array was positioned at the center of the display screen.

Procedure. Subjects were instructed to "respond as quickly as possible without making too many mistakes-an error rate of $10 \%$ is acceptable." 3 Subjects initiated a trial by depressing two telegraph keys aligned side by side. Responses were signaled by lifting one of the keys-the left key if a $P$ or a $C$ appeared in the stimulus array, and the right key if an $R$ or $G$ was present. Feedback about response latency and accuracy was provided on each trial by two computer-activated audio oscillators.

The sequence of events on each trial was as follows. Upon initiation of the trial, a fixation cross appeared at the center of the display for $500 \mathrm{msec}$. After an interval of $200 \mathrm{msec}$, a stimulus item appeared for $250 \mathrm{msec}$. Upon stimulus offset, a continuous high-pitched tone was activated. The subject was instructed to "minimize the duration of the tone by responding as quickly as you can," and the tone was terminated by the subject's response. When the subject's response was correct, a second low-pitched tone was activated for $200 \mathrm{msec}$. The intertrial interval was selfpaced. Reaction time was defined as the interval from the onset of the stimulus item to the onset of the subject's response.

The subjects were tested in five daily 1 -h sessions. Within a session, there were three blocks of test trials, 96 trials per block, with a short break after every 48 trials. ${ }^{4}$ In the first test session, the subjects were familiarized with the apparatus and stimulusresponse mapping. In addition, the subjects were given 15 practice trials per condition. In subsequent sessions, the subjects were given six practice trials per condition. Test trials were blocked by stimulus type, and each block of 96 trials was composed of 12 stimuli presented eight times. The order of trial blocks was randomly determined, and under the constraints described above, the stimulus appearing on any particular trial was randomly determined.

The subjects were seated in a dimly lit room at a distance of $88 \mathrm{~cm}$ from the display. Viewing was binocular and the subjects used a chinrest.

\section{Results}

Mean reaction times (for all responses) as well as mean percentage correct are shown in Figure 1. The reaction time data are considered first. ${ }^{5}$ Inspection of Figure 1 suggests that subjects responded more quickly to words $(\bar{X}=435 \mathrm{msec})$ and consonantvowel nonwords ( $\bar{X}=433 \mathrm{msec})$ than to consonant nonwords $(\bar{X}=466 \mathrm{msec})$. An analysis of variance indicated a significant main effect of stimulus type $[F(2,8)=22.93, \quad p<.001] . \quad$ A Newman-Keuls analysis confirmed that words and consonant-vowel nonwords were responded to more quickly than the consonant items. No other effects of the reaction time analysis were significant and all were $\mathrm{p}>.1$, 

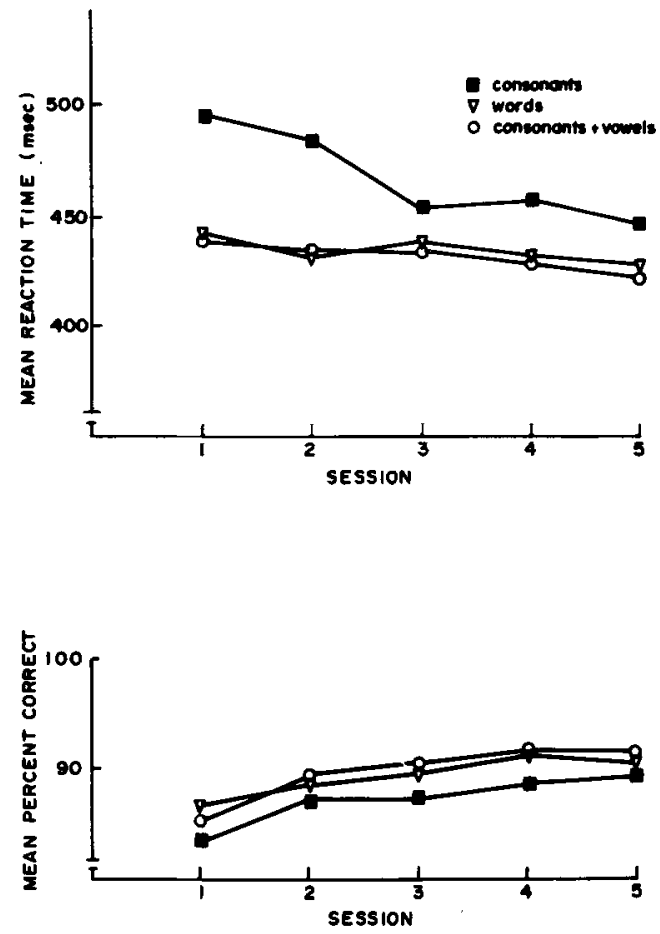

Figure 1. Mean response times and mean percentage correct (Experiment 1) for words, consonant-vowel nonwords, and consonant nonwords on Days 1-5.

with the exception of the Stimulus Type by Test Session interaction $(p<.091)$.

With respect to error rates, the subjects performed more accurately on words $(\bar{X}=89 \%$ correct $)$ and consonant-vowel nonwords ( $(\bar{X}=89 \%$ correct $)$ than on consonant nonwords $(\bar{X}=87 \%$ correct $)$. Thus, the error data are in accord with the reaction time data. An analysis of variance, however, revealed no significant effects, all $\mathrm{p}>$.1.

These data replicate the Carr et al. (1976) findings. The subjects performed better on words than on consonant nonwords. The word superiority disappears, however, when vowels are added to the nonword items - there was no difference between words and consonant-vowel nonwords.

\section{EXPERIMENT 2}

The results of Experiment 1 are consistent with a conceptual category interpretation of the word superiority effect. When subjects search for consonant targets, they process consonant-vowel stimuli (words or nonwords) more quickly than all-consonant stimuli. This result, however, is open to several interpretations. It could be argued that the consonantvowel nonwords are highly familiar - they look like words and can be pronounced like words; many are syllables or word roots. Thus, orthographic familiarity or pronounceability may have mediated the result in Experiment 1.
In Experiment 2, therefore, we had subjects process consonant-number stimuli that were neither orthographically familiar nor easy to pronouncefor example, P4S, 8P7, and T7P. If subjects are using conceptual category information to mediate their responses, then they should perform as well on the consonant-number stimuli as on the consonantvowel stimuli. Alternatively, if subjects are using orthography or pronounceability, then they should perform better on consonant-vowel stimuli than on consonant-number stimuli.

Experiment 2 also addresses another issue in the word superiority literature-the relative difficulty of words vs. single letters. Carr et al. found that subjects could identify a target letter presented in a word context more readily than a target letter presented alone. The results of several previous studies, however, suggest that the poor single-letter performance in the Carr et al. study was probably due to positional uncertainty (Estes, 1975) and masking (Johnston \& McClelland, 1973) in the display. In the present study, no masking was used and the positional uncertainty of single letters was reduced by the insertion of dashes in nontarget locations. Under these conditions, we expected single-letter targets to be processed more readily than targets embedded in the multielement alphanumeric displays.

\section{Method}

Subjects. Five new Vanderbilt University students (two male, three female) were tested individually in three consecutive daily sessions. Two additional follow-up sessions were conducted within 1 week of the initial testing. Each subject was paid $\$ 3$ per session.

Stimuli and Apparatus. The apparatus, as well as the consonantvowel nonwords, were the same as in Experiment 1. Two new stimulus types designed for this study were consonant-numbers and consonant-dashes: P4S, R4S, C4S, G4S, 8R7, 8P7, 8C7, 8G7, T7P, T7R, T7C, T7G; and P--, R--, C--, G--, -P-, -R-, -C-, $-G-,--P,--R,--C,--G$.

Procedure. With the following exceptions, the procedure was the same as in Experiment 1. There were six blocks of test trials per session, with 96 trials per block. Subjects were explicitly told that vowels, numbers, and dashes were nontargets. During Days 1-3 of testing, the subjects saw all three stimulus types. During Days 4 and 5, only consonant-vowel and consonantnumber stimuli were presented.

\section{Results}

Sessions 1-3. Mean reaction times and mean percentage correct are shown in Figure 2. With regard to reaction times for Days 1-3, the data in Figure 2 suggest that performance varied as a function of stimulus type, and this main effect was significant $[F(2,8)=16.12, p<.002]$. A Newman-Keuls analysis revealed that subjects responded more quickly to consonant-dashes $(\bar{X}=409 \mathrm{msec})$ than to consonant-vowels ( $\bar{X}=419 \mathrm{msec})$, and more quickly to consonant-vowel items than to consonant-numbers $(\bar{X}=427 \mathrm{msec})$. The main effect of test session was also significant $[F(2,8)=4.81, p<.042]$. Subjects improved with practice. 

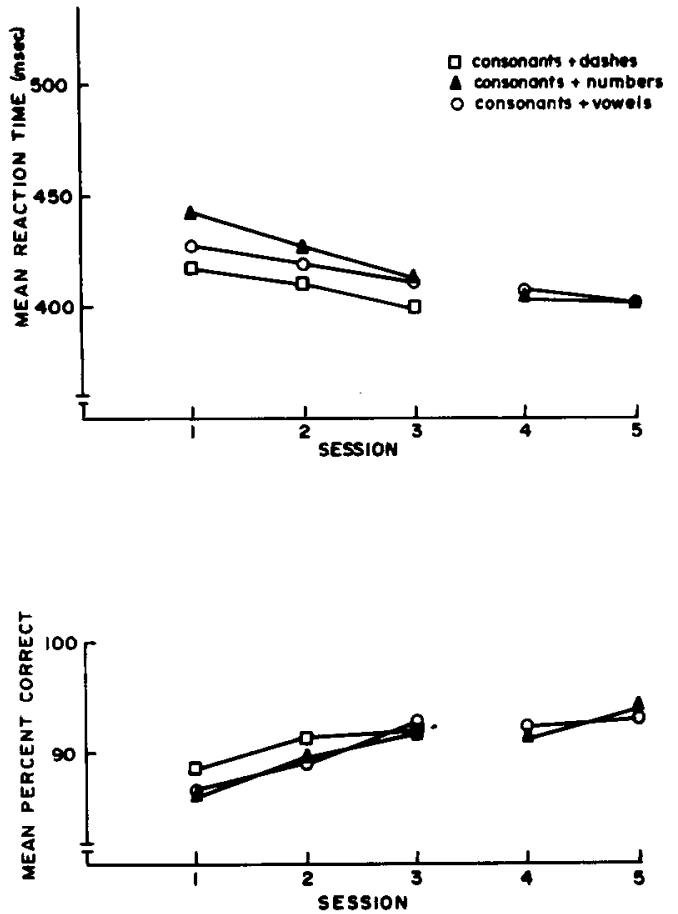

Figure 2. Mean response times and mean percentage correct (Experiment 2) for consonant-dash items on Days 1-3 and for consonant-vowel and consonant-number items on Days 1-5.

Inspection of Figure 2 suggests that, with practice, the level of performance on consonant-number stimuli approaches the level of performance on consonant-vowel stimuli. Indeed, there was a significant interaction between test session and stimulus type $[F(4,16)=3.38, p<.034]$. Newman-Keuls tests suggested several sources of this interaction: In Session 1 , the three stimulus types were significantly different from one another; in Session 2, the consonant-number condition was slower than the consonant-dash condition; and in Session 3, the consonant-vowel and consonant-number conditions were slower than the consonant-dash condition. For the most part, the Test Session by Stimulus Type interaction reflects the convergence of performance on consonant-vowel and consonant-number stimuli with practice.

The analysis of variance also revealed a Stimulus Type by Target Display Position interaction $[F(4,16)$ $=4.41, \mathrm{p}<.013]$. At the first position, consonantnumber stimuli were responded to more slowly than the other two stimulus types. At the middle position, the subjects responded most quickly to consonantdashes, followed by consonant-vowels, followed by consonant-numbers. At the third position, the subjects responded more quickly to the consonant-dash stimuli than to the other two stimulus types. We have no interpretation of this interaction.

No other effects of the analysis of variance on reaction times were significant (all $p>.1$ ).
We turn now to the error data for Days 1-3. Consistent with the reaction time data, there was a significant improvement with practice $[F(2,8)=5.62$, $p<.03]$. No other effects of the error analysis were significant (all $\mathrm{p}>.1$ ).

Sessions 4-5. In Test Sessions 4 and 5 , the subjects judged only consonant-vowel and consonant-number stimuli. As shown in Figure 2, there were no apparent differences between these conditions on Days 4 and 5. An analysis of variance on reaction times confirmed this observation. No effects were significant, and all were $\mathrm{p}>.1$, with the exception of the main effect of display position $(p<.067)$ and the interaction between display position, stimulus type, and test session $(p<.067)$.

A companion analysis of errors revealed no significant effects (all $\mathrm{p}>.1$ ).

Summary. In contrast with Experiment 1, there was a significant improvement with practice, probably because subjects in Experiment 2 were tested more extensively. Secondly, and in contrast with Carr et al. (1976), the subjects responded more quickly to single target letters than to targets embedded in consonantvowel or consonant-number items. Presumably, the single-letter superiority in the present case is due to the insertion of dashes in nontarget locations (thereby reducing positional uncertainty about target location) as well as the absence of masking. Finally, and contrary to prediction, on Days 1-3, the subjects responded more quickly to consonant-vowel stimuli than to consonant-number stimuli. However, performance on these two conditions converged quickly with practice. Thus we have some support, albeit qualified, for the conceptual category hypothesis.

\section{EXPERIMENT 3}

In Experiment 1, we found that performance on consonant-vowel stimuli was superior to performance on all-consonant stimuli. In Experiment 2, we found that performance on consonant-number stimuli quickly reaches the level of performance on consonant-vowel stimuli. In fact, the two conditions were not statistically different by the end of the second test session. This evidence supports a conceptual category explanation of the word superiority effect obtained in Experiment 1.

However, the results of Experiments 1 and 2 are not directly comparable. Subjects had less practice in Experiment 1 than in Experiment 2, and there was no significant improvement with practice in Experiment 1. Even so, there was a hint of a Stimulus Type by Test Session interaction in Experiment 1 ( $p<.091$ ); thus with more practice, performance on the all-consonant items might have converged with performance on the other two stimulus types. What we need, therefore, is a direct within-subject comparison between the all-consonant, consonant-number, 
and consonant-vowel conditions. Experiment 3 meets this need.

\section{Method}

Subjects. Five new Vanderbilt University students (three male, two female) were tested individually in five consecutive daily sessions. Each was paid \$3 per session.

Stimuli and Apparatus. The stimuli were the all-consonant items, the consonant-vowel items, and the consonant-number items used previously. The apparatus was the same as in Experiment 1.

Procedure. The procedure was the same as in Experiment 1, with the following exceptions. There were six blocks of test trials per session, with 96 trials per block. The subjects were explicitly told that vowels and numbers were nontargets.

\section{Results}

Mean reaction times and mean percentage correct are illustrated in Figure 3. Inspection of Figure 3 suggests that subjects responded more quickly to consonant-vowel items $(\bar{X}=426 \mathrm{msec})$ and consonant-number items $(\bar{X}=424 \mathrm{msec})$ than to all-consonant items $(\bar{X}=441 \mathrm{msec})$. An analysis of variance indicated that the main effect of stimulus type was significant $[F(2,8)=10.43, p<.006]$. Newman-Keuls tests confirmed that the all-consonant items were responded to more slowly than the other two stimulus types. The main effect of test session was also significant $[F<4,16)=30.77, p<.001]$. As in Experiment 2, the subjects improved with practice.
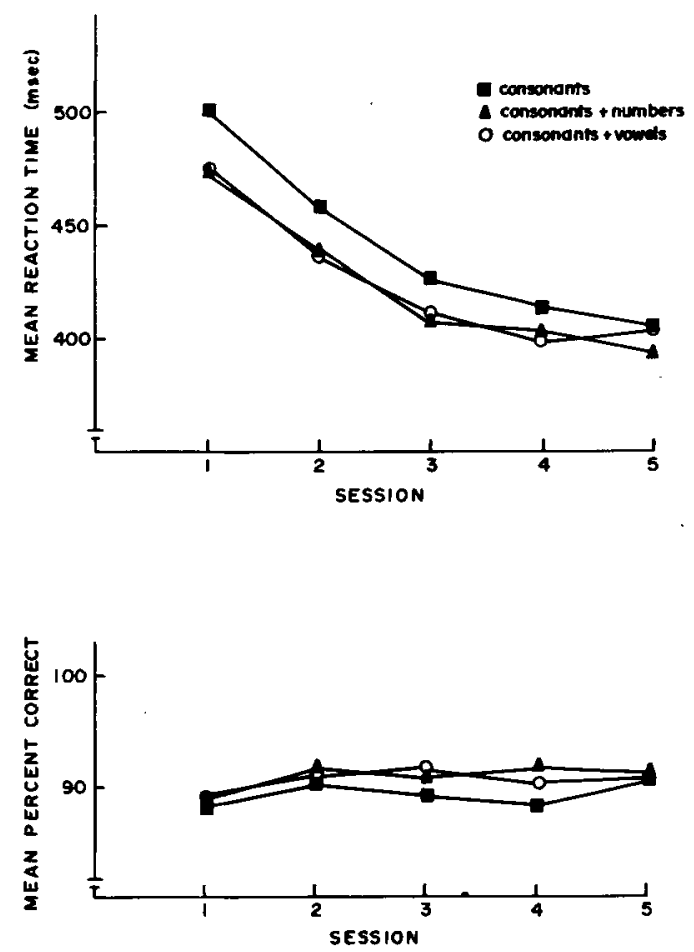

Figure 3. Mean response times and mean percentage correct (Experiment 3) for consonant, consonant-vowel, and consonantnumber items on Days 1-5.
The analysis also revealed an interaction between stimulus type and display position $[F(4,16)=11.04$, $\mathrm{p}<.001]$. Newman-Keuls tests indicated that responses to the all-consonant items were significantly slower at the third display position, but there were no significant differences between conditions at Display Positions 1 and 2. We have no interpretation of this effect, particularly since it is not consistent with results found in Experiments 1 and 2.

There was also a significant interaction between stimulus type, display position, and test session $[F(16,64)=3.64, p<.001]$. This interaction was due primarily to improvement with practice on the consonant items in which the target appeared in the third display position. Apparently, subjects initially adopted a left-to-right search through consonant items and gradually shifted to a parallel search strategy as they learned the distinctive features of the stimulus set (a similar pattern is found in the error data-see below).

No other effects of the the reaction time analysis were significant, and all were $\mathrm{p}>.1$, with the exception of the Test Session by Display Position interaction $(\mathrm{p}<.063)$.

With respect to the error data, there was a significant Stimulus Type by Display Position interaction $[F(4,16)=5.07, p<.008]$. In accord with the reaction time data, the subjects were significantly less accurate on the all-consonant items at Display Position 3. There was also a significant Stimulus Type by Display Position by Test Session interaction $[F(16,64)=1.83, p<.045]$. No other effects were significant (all $\mathrm{p}>.1$ ).

To sum up, the subjects performed better on the consonant-vowel and consonant-number items than on the all-consonant items. This difference was most pronounced at Display Position 3. Also, and as in Experiment 2, performance improved with practice.

\section{EXPERIMENT 4}

Experiments 1-3 suggest that subjects may use conceptual category information to facilitate letter detection. Subjects searched for consonant targets more quickly when they were embedded in consonantnumber and consonant-vowel strings than in allconsonant strings. Thus, it seems that it was easier to search through conceptually heterogeneous stimuli than through homogeneous ones. There is, however, another possible interpretation of these data.

Logically, stimuli which differ in the conceptual domain must also differ psychophysically. Conversely, items which cannot be discriminated are unlikely to belong to separate conceptual categories. Furthermore, White (1977) has recently shown that the conceptual category effect may, in fact, be mediated by psychophysical attributes of the stimuli. 
In the present case, there are at least two psychophysical dimensions which may have led to relatively better performance on the word, consonant-vowel. and consonant-number items-letter symmetry and directionality. All the distractor letters in the words (as well as three of four in the consonant-vowel nonwords) were symmetrical. In addition, the distractors in the consonant-number items were either symmetrical $(8, T)$ or left-facing $(4,7)$. In contrast, the targets as well as all-consonant distractors were all asymmetrical and right-facing. Thus, it seems possible that letter symmetry and directionality may have mediated the word and nonword superiority effects obtained above.

In Experiment 4, therefore, we used a new set of all-consonant items containing letter distractors which geometrically resembled those in the word items (e.g., words $=\mathrm{O}, \mathrm{T}, \mathrm{A}, \mathrm{E}$; nonwords $=\mathrm{D}, \mathrm{T}$, $H, F)$. If subjects use conceptual category information to mediate their responses, then they should perform better on words than on either the new or old all-consonant lists. However, if subjects are sensitive to letter psychophysics, then they should perform better on words and on the new all-consonant items than on the old all-consonant items. In fact, the latter result was obtained.

\section{Method}

Subjects. Five new subjects (one male, four female) were tested individually in five daily sessions. Each was paid $\$ 3$ per session.

Stimuli and Apparatus. The apparatus, as well as the words and old all-consonant items, were the same as in Experiment 1. The new all-consonant items were PDT, CDT, RDT, GDT, HPF, HRF, HCF, HGF, THP, THR, THC, THG.

Procedure. The procedure was the same as in Experiment 1, except that there were six blocks of test trials per session, with 96 trials per block.

\section{Results $^{6}$}

Mean reaction times as well as mean percentage correct are shown in Figure 4. The subjects responded more quickly to words $(\bar{X}=437 \mathrm{msec})$ and to the new all-consonant items ( $\bar{X}=441 \mathrm{msec})$ than to the old all-consonant items $(X=463 \mathrm{msec})$. An analysis of variance indicated that the main effect of stimulus type was significant $[F(2,8)=12.07, p<.004]$. Newman-Keuls tests confirmed that targets were discriminated more slowly in the old all-consonant items than in the other two types of items. As in Experiments 2 and 3, the subjects improved with practice, and the main effect of test session was significant $[F(4,16)=29.55, \mathrm{p}<.001]$.

The analysis also revealed an interaction between stimulus type and display position $[\mathrm{F}(4,16)=8.53$, $\mathrm{p}<.001]$. Newman-Keuls tests indicated that responses to the new all-consonant items were significantly slower than responses to the words at the first display position, while these conditions did not
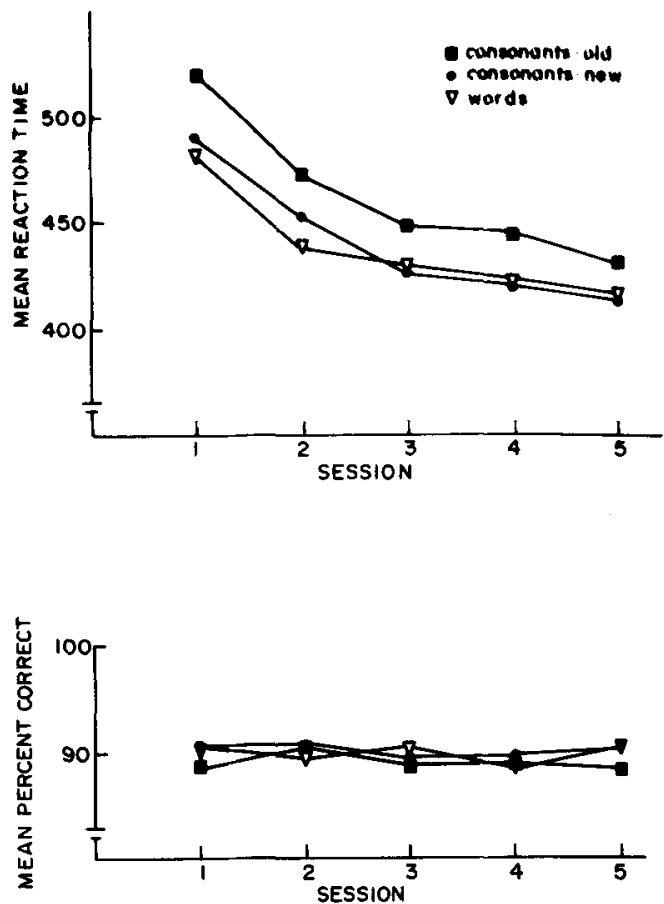

Figure 4. Mean response times and mean percentage correct (Experiment 4) for old consonant, new consonant, and word items on Days 1-5.

differ at Display Positions 2 and 3. However, performance on the old all-consonant list was consistently slower than the other two conditions at all three display positions.

There was also a significant interaction between stimulus type, test session, and display position $[F(16,64)=2.07, p<.05]$. As in Experiment 3, this interaction was due in part to improvement with practice on the old consonant items in which the target appeared in the third display position. No other effects of the reaction time analysis were significant (all $\mathrm{p}>.15$ ).

With respect to the error data, there were no significant effects (all $\mathrm{p}>.15$ ).

In summary, the subjects performed better on words and new consonant items than on the old consonant items. Also, and as in Experiments 2 and 3, performance improved with practice.

\section{DISCUSSION}

The present results have both theoretical and methodological implications. With respect to theory, two major hypotheses are at issue. One hypothesis (Massaro, 1973) states that subjects use their knowledge of orthographic redundancy to restrict the set of letter alternatives in words. In contrast, Carr et al. (1976) suggest that linguistic knowledge can directly enhance the perception of letters in words. Neither 
hypothesis explains the pattern of word and nonword superiority effects obtained in the present study. The consonant-vowel superiority in Experiment 1, the consonant-number superiority in Experiments 2 and 3 , and the all-consonant superiority in Experiment 4 indicate that linguistic knowledge in any form (e.g., semantics, orthography, pronounceability) need not mediate the word-superiority effect.

Instead, subjects in the present task capitalize on the psychophysical and/or conceptual relationships between target and distractor items. In Experiments 1-3, distractor letters in consonant-vowel and consonantnumber items were conseptually as well as psychophysically distinct from target letters-and the subjects performed relatively well on these items. Since conceptual and psychophysical information was confounded in Experiments 1-3, an effort was made to uncorrelate these two sources of information in Experiment 4. There, subjects judged conceptually homogeneous consonant items which contained psychophysically "simple" distractors. The subjects responded as quickly to these new consonant items as to words. While the role of conceptual categories can't be completely ruled out, Experiment 4 furnishes strong evidence that letter psychophysics played a predominant role in mediating the observed effects. ${ }^{7}$

The results of Experiment 4 are in accord with other reports that visual similarity influences letter and word processing (Massaro \& Klitzke, 1977). They are not in agreement, however, with a recent study by Purcell, Stanovich, and Spector (1978). Using a letter detection task, Purcell et al. (Experiments 1 and 2) obtained word superiority even though the nonwords contained geometrically simple distractors ( $\mathrm{V}$ and $\mathrm{H})$. This outcome could be accounted for by the conceptual category hypothesis, but not by the psychophysical one. There are, however, many procedural differences between Purcell et al. and the present case (mixed vs. blocked presentation of test items; positional certainty vs. uncertainty of target items; accuracy vs. speed and accuracy measurement; mask vs. no mask). Of particular importance may be the use of a pattern mask in the Purcell et al. study, while none was used herein. As we have previously argued (see Footnote 2), a pattern mask may introduce an uncontrolled source of variance, and it seems possible that the mask used by Purcell et al. was geometrically more similar to the nonword than to the word items. Thus, stimulus/mask psychophysics may have mediated the Purcell et al. outcome, and it seems possible that other discrepancies in the literature may be accounted for by this factor (see, for instance, Johnston \& McClelland, 1973).

While the present results have general methodological implications, they do not apply to every previous study of word superiority. The design of some studies, by including nonwords which are anagrams of word items, obviates the use of psychophysical information about individual letters to achieve word superiority (e.g., Estes, 1975; Spector \& Purcell, 1977). The important point here is that when psychophysical information is available, subjects are able to use it.

The contribution of the present study can be viewed as part of the continuing debate about the locus of the effects of linguistic knowledge on word processing. Our results cast doubt on the Carr et al. hypothesis that linguistic knowledge can directly facilitate perceptual resolution of words. Instead, psychophysical differences between target and distractor letters can account for faster target search through word as well as nonword arrays.

This leaves little or no evidence that linguistic knowledge directly facilitates perceptual analysis. When physical stimulus properties are adequately controlled and a word superiority effect is obtained, the effect is probably due to linguistic redundancy (e.g., Massaro, 1975). Such contextual redundancy reduces the effective set of letter alternatives, thereby simplifying the discrimination task rather than altering the perceptual process itself.

\section{REFERENCE NOTE}

1. Posner, M., Synder, C. R. R., \& Davidson, B. J. Attention and the detection of signals. Paper presented at the Eighteenth Annual Meeting of the Psychonomic Society, Washington, D.C., November 10-12, 1977.

\section{REFERENCES}

BRAND, J. Classification without identification in visual search. Quarterly Joumal of Experimental Psychology, 1971, 23, 178-186.

Carr, T. H., Lehmkuhle, S. W., Kottas, B., Astor-Stetson, E. C., \& ARNold, D. Target position and practice in the identification of letters in varying contexts: A word superiority effect. Perception \& Psychophysics, 1976, 19, 412-416.

Coffin, S. Spatial frequency analysis of block letters does not predict experimental confusions. Perception \& Psychophysics, $1978,23,69-74$.

Egeth, H. Selective attention. Psychological Bulletin, 1967, 67, 41.57 .

Egeth, H., Jonides, J., \& W WLl, S. Parallel processing of multielement displays. Cognitive Psychology, 1972, 3, 674-698.

Estes, W. K. The locus of inferential and perceptual processes in letter identification. Journal of Experimental Psychology: General, 1975, 105. 122-145.

GIBSON. E. J. Principles of perceptual learning and development. New York: Appleton-Century-Crofts, 1969.

Gleitman, H., \& Jonides, J. The cost of categorization in visual search: Incomplete processing of target and field items. Perception \& Psychophysics. 1976. 20, 281-288.

GREeN, D. M.. \& Birdsall, T. G. Detection and recognition. Psychological Review, 1978, 85, 192-206.

HABER, R. N. The nature of the effect of set on perception. Psychological Review, 1966, 73, 335-350.

IngLiNG, N. W. Categorization: A mechanism for rapid information processing. Joumal of Experimental Psychology, 1972, 94, 239.243. 
Johnston, J. C., \& MCClelland, J. L. Visual factors in word recognition. Perception \& Psychophysics, 1973, 14, 365-370.

Jonides. J., \& Gleitman, H. A conceptual category effect in visual search: 0 as a letter or as a digit. Perception \& Psychophysics, 1972, 12, 457-460.

Jonides, J., \& Gleitman, H. The benefit of categorization in visual search: Target location without identification. Perception \& Psychophysics, 1976, 20, 289-298.

JULEsz, B. Foundations of cyclopean perception. Chicago: University of Chicago Press, 1971.

KRUEGER, L. E. Familiarity effects in visual information processing. Psychological Bulletin, 1975, 82, 949-974.

LAPPIN, J. S. The relativity of choice behavior and the effect of prior knowledge on the speed and accuracy of recognition. In F. Restle \& N. Castellan (Eds.), Cognitive theory (Vol. 3). Hillsdale, N.J: Erlbaum, 1978.

Lindsay, P. H., \& Norman, D. A. Human information processing. New York: Academic Press, 1972.

Massaro, D. W. Perception of letters, words, and non-words. Journal of Experimental Psychology, 1973, 100, 349-353.

Mass ARo, D. W. Understanding language. New York: Academic Press. 1975.

Massaro, D. W., \& Klitzke, D. Letters are functional in word identification. Memory \& Cognition, 1977, 5, 292-298.

Pomerantz, J. R. Pattern goodness and the speed of encoding. Memory \& Cognition, 1977, 5, 235-241.

Purcell. D. G., Stanovich, K. E., \& Spector, A. Visual angle and the word superiority effect. Memory \& Cognition, 1978, 6. $3-8$.

REICHER. G. M. Perceptual recognition as a function of meaningfulness of stimulus material. Journal of Experimental Psychologv, 1969, 81, 275-280.

Reinvang, I. Perception and generation of mirror-inverted letters. Scandinuvian Journal of Psychology, 1972, 13, 385-291.

Schneider, W., \& Shiffrun, R. M. Controlled and automatic human information processing: I. Detection, search and attention. Psychological Review, 1977, 84, 1-66.

Sekuler, R., \& Ball, K. Mental set alters visibility of moving targets. Science, 1977, 198, 60-62.

Shiffrin, R. M., \& Schneider, W. Controlled and automatic human information processing: II. Perceptual learning, automatic attending and a general theory. Psychological Review, 1977. 84. 127-190.

Spector. A., \& PUrcell, D. G. The word superiority effect: A comparison between restricted and unrestricted alternative set. Perception \& Psychophysics, 1977, 21, 323-328.

Staller, J. A study of mirror image discrimination in humans. Unpublished master's thesis, Northwestern University, 1974.

Staller. J., \& Sekuler, R. Stimulus and response factors in mirror-image discrimination. Perception \& Psychophysics, 1977, 22. $592-598$.

Thompson, M. C., \& Massaro, D. W. The role of visual information and redundancy in reading. Journal of Experimental Psy. chology, 1973, 98, 49-54.

TownsEND, J. T. Theoretical analysis of an alphabetic confusion matrix. Perception \& Psychophysics, 1971, 9, 40-50.

UTTAL, W. R. An autocorrelation theory of form detection. Hillsdale, N.J: Erlbaum, 1975.

WhITE, M. J. Identification and categorization in visual search. Memory \& Cognition, 1977, 5, 648-657.

\section{NOTES}

1. Other stimulus dimensions (e.g., curvature or diagonality) may be important. Determination of the specific dimensions involved is beyond the scope of this paper.

2. We made these procedural changes for several reasons. We regard pattern masking in this paradigm as a potential uncontrolled source of variance. There is no guarantee that a pattern mask will have the same effect on different patterned stimuli in different conditions. As an alternative to masking, we chose a speeded response time task which put sufficient demand on subjects to discriminate between experimental conditions. We measured both speed and accuracy to insure that our comparisons were undistorted by speed-accuracy tradeoffs.

3. We encouraged the relatively high error rate $(10 \%)$ with the expectation that, as in Carr et al. (1976), errors could be used to discriminate between conditions. Using the guideline procedure, we expected reaction times to be equivalent and accuracy to vary between conditions. In fact, errors were essentially equivalent and reaction time varied. This does not diminish the relevance of our results, since reaction time and errors are isomorphic measures of choice behavior (Lappin, 1978).

4. In addition to the $250-\mathrm{msec}$ guideline, the subjects were given an equal number of trials at a 400-msec guideline in Experiment 1. A procedural problem arose which precluded meaningful analysis of these data. There were a large number of anticipation errors in the data-subjects responded before stimulus offset. Furthermore, because of hardware limitations, reaction time was not recorded on these trials. Thus, we felt that available data would not provide a reliable estimate of performance.

5. In our preliminary analysis of Experiments 1 and 3, we derived composite scores based on reaction time and error data. The method was as follows. We calculated centroids for each stimulus condition and fitted a linear discriminant function through these centroids. A subject's composite score for a particular data point was then derived by projecting that data point onto the linear discriminant function. In the process of doing this, we found that errors had virtually no influence on the weighted scores. Since reaction time and errors did not covary, we decided to present the data separately instead of in composite form. However, the results obtained using the potentially more powerful composite scores were statistically equivalent to the simpler reaction time results reported here.

6. In Experiment 4, one subject responded more quickly to the old consonant items than to the word or new consonant items. We felt this response pattern was anomalous and therefore discarded the data. An additional subject was tested to make up for the loss.

7. Our analysis of the role of letter psychophysics has also proceeded along other avenues of inquiry. In particular, we evaluated the stimuli in Experiments 1-3 in terms of theoretical and empirical letter confusion matrices. The degree of "overlap" or "similarity" between target and distractor letters in each stimulus item provides an index of target discriminability for that particular stimulus. On this basis, mean confusion values for each stimulus type were derived. Three theoretical pattern measures-the feature model (Gibson, 1969), the autocorrelation model (Uttal, 1975), and the fourier model (Coffin, 1978)-were used. In addition, confusion matrices based on empirical data for uppercase letters were also consulted (Townsend, 1971). We found that the autocorrelation indices and, to a lesser extent, the fourier indices were in closest agreement with our reaction time results-both measures indicated a higher degree of target/distractor similarity for the old all-consonant items than for the other stimulus types. Additional details are available on request.

(Received for publication September 25, 1978; accepted November 15,1978 .) 